PREPRINT OF ACCEPTED MANUSCRIPT. PLEASE CITE AS

Crane, M. E., Phillips, K. E., Maxwell, C. A., Norris, L. A., Rifkin, L. S., Blank, J. M., Sorid, S. D., Read, K. L., Swan, A. J., Kendall, P. C., \& Frank, H. E. (2021). A qualitative examination of a school-based implementation of computer-assisted cognitive-behavioral therapy for child anxiety. School Mental Health, 13(2), 347-361. https://doi.org/10.1007/s12310-021-09424-y

A Qualitative Examination of a School-Based Implementation of Computer-Assisted Cognitive-Behavioral Therapy for Child Anxiety

Margaret E. Crane, M.A. ${ }^{1}$, Katherine E. Phillips, M.A. ${ }^{1}$, Colleen A. Maxwell, M.A. ${ }^{1}$, Lesley A. Norris, M.A. ${ }^{1}$, Lara S. Rifkin, M.A. ${ }^{1}$, Jacob M. Blank ${ }^{1}$, Samantha D. Sorid ${ }^{2}$, Kendra L. Read, Ph.D. ${ }^{3}$, Anna J. Swan, Ph.D. ${ }^{4}$, Philip C. Kendall, Ph.D. ${ }^{1}$, Hannah E. Frank, Ph.D. ${ }^{1,5}$

${ }^{1}$ Temple University, Department of Psychology, Philadelphia, PA, United States

${ }^{2}$ The College of William and Mary, Department of Psychological Sciences, Williamsburg, VA, United States

${ }^{3}$ University of Washington School of Medicine, Department of Psychiatry and Behavioral Sciences, Seattle, WA, United States

${ }^{4}$ University of California, San Francisco, Department of Psychiatry and Behavioral Sciences, San Francisco, CA, United States

${ }^{5}$ Warren Alpert Medical School of Brown University, Department of Psychiatry and Human Behavior, Providence, RI, United States

Author's Note: Correspondence should be addressed to Margaret E. Crane, Temple University, Department of Psychology, Weiss Hall, 1701 N. 13th Street, Philadelphia, PA 19122. E-mail: margaret.crane@temple.edu. Telephone: +1 617-966-2403. Fax: +1-215-204-0565. Philip C. Kendall, e-mail: pkendall@ temple.edu.

Declarations: This project was funded by a National Institute of Mental Health (NIMH) research grant awarded to Philip C. Kendall (R01MH086438). Manuscript preparation was supported by NIMH grants (F31MH124346 to Mrs. Crane; F31MH123038 to Mrs. Norris; F31MH112211 to Dr. Frank). Dr. Kendall receives royalties from the sales of published materials related to the treatment of youth, and his spouse operates and receives income from the publisher. 


\begin{abstract}
Mental health treatment in schools has the potential to improve youth treatment access. However, school-specific barriers can make implementing evidence-based interventions difficult. Task-shifting (i.e., training lay staff to implement interventions) and computer-assisted interventions may mitigate these barriers. This paper reports on a qualitative examination of facilitators and barriers of a school-based implementation of a computer-assisted intervention for anxious youth (Camp Cope-A-Lot; CCAL). Participants $(N=45)$ included school staff in first through fourth grades. Providers attended a training in CCAL and received weekly, hour-long group consultation calls for three months. In the second year, the sustainability of CCAL use was assessed. Qualitative interviews were conducted after the first year (initial implementation) and second year (sustainability). Interviews were analyzed using the Consolidated Framework for Implementation Research domains to classify themes. Although participants reported that CCAL included useful skills, they expressed concerns about recommended session length (45 minutes) and frequency (weekly). Time burden of consultation calls was also a barrier. School staff facilitated implementation by enabling flexible scheduling for youth to be able to participate in the CCAL program. However, the sustainability of the program was limited due to competing school/time demands. Results suggest that even with computer assisted programs, there is a need to tailor interventions and implementation efforts to account for the time restrictions experienced by school-based service providers. Optimal fit between the intervention and specific school is important to maintain the potential benefits of computer-assisted treatments delivered by lay service providers in schools. Keywords. Computer-assisted treatment, cognitive-behavioral therapy, schools, child anxiety, implementation.
\end{abstract}




\section{A qualitative examination of a school-based implementation of computer-assisted cognitive-behavioral therapy for child anxiety}

Anxiety disorders are the most common mental health problem among school-aged children and are associated with ongoing impairments in social, academic, and family functioning when left untreated (Costello et al., 2003; Merikangas et al., 2010; Swan \& Kendall, 2016). Although cognitive-behavioral therapy (CBT) has been identified as a well-established, evidence-based intervention (EBI) for youth anxiety disorders (Hollon \& Beck, 2013; Kendall et al., 2008; Walkup et al., 2008), the vast majority of youth with mental health needs do not receive services (Kataoka et al., 2002). Of those youth who do receive mental health services, $75 \%$ receive them through school (Farmer et al., 2003). In the United States, public schools represent the largest providers of mental health services to youth (Hazen et al., 2004; Merikangas et al., 2011; Rones \& Hoagwood, 2000). As such, the school setting can improve access to mental health services and can even serve to ameliorate ethnic disparities in the receipt of mental health care (Allensworth et al., 1997; Cooper, 2008; Kataoka et al., 2007). School-based mental health services are often viewed as more acceptable by families, thus increasing the likelihood of utlization (Atkins et al., 2017; Farmer et al., 2003; Husky et al., 2011). Federal and state policies have emphasized the importance of implementing EBIs in schools (U.S. Department of Education Office of Special Education and Rehabilitative Services, 2002).

Given both the prevalence of anxiety disorders in school-aged youth, and the robust findings in support of CBT for youth anxiety, anxiety-disordered youth are a logical target for school-based interventions. Studies have shown that school-based mental health treatment can be effective for a number of youth disorders (Franklin et al., 2012; Owens et al., 2014; Rones \& Hoagwood, 2000). Given that school mental health providers often have limited time to implement EBIs (Owens et al., 2014; Sulkowski et al., 2012), studies have evaluated the use of lay mental health staff to implement EBIs. There is evidence that teachers and school nurses can effectively implement CBT for youth with anxiety (Barrett \& Turner, 2001; Stallard et al., 2007). Despite evidence of their effectiveness, EBIs still are not commonly used in the school setting (Owens et al., 2014). There is still much that is unknown about implementing EBIs in schools, and it is a setting that comes with a unique set of barriers (Eiraldi et al., 2015).

Although implementation science has moved beyond simply identifying implementation determinants, there is a need to examine how such determinants interact to affect implementation (Powell et al., 2019). The success of school-based programs is often contingent on interconnected factors such as administrative buy-in, parent 
involvement, space and time restrictions, and overlapping responsibilities. Implementation frameworks, such as the Consolidated Framework for Implementation Research (CFIR; Damschroder et al., 2009), can contextualize barriers and facilitators to implementation by examining implementation determinants across various levels. CFIR articulates five major domains: (1) implementation process, (2) intervention characteristics, (3) inner setting, (4) individual characteristics of practitioners and implementation team members, and (5) outer setting. When considering implementation in school settings, facilitators and barriers have been identified across all CFIR levels as described below (Langley et al., 2010).

The majority of examined barriers to successful school-based implementation exist within the inner setting (i.e., the location in which a program is implemented). Numerous studies have identified school-specific barriers such as competing responsibilities, and limited space and time (Forman et al., 2009; Langley et al., 2010). Most schools have a 9-month calendar, with distinctive bursts of activity such as state testing, grading periods, holiday, and summer breaks. This schedule can hinder consistent training, consultation, and treatment, thus impeding successful program implementation (Owens et al., 2014). Further, teachers are often hesitant to allow students to miss academic time due to the pressures of meeting benchmarks and standardized testing (Nadeem et al., 2011). High staff turnover and competing responsibilities also are barriers to integrating EBIs into existing school structures (Fiscella \& Kitzman, 2009; Forman et al., 2009; Mellin \& Weist, 2011). Conversely, two qualitative studies have found that increased EBI uptake is associated with school leadership that makes implementing EBIs a priority, schools with a formally appointed implementation leader, and schools with existing supports for delivering EBIs (Hudson et al., 2020; Locke et al., 2018).

Other CFIR constructs have been examined less frequently in school settings. The implementation process includes steps to initiate EBIs such as training and consultation. Lack of adequate time to thoroughly engage school staff in these activities can prove detrimental to implementation initiatives (Mellien \& Weist, 2011; Rubinson, 2002). Individual characteristics of practitioners and implementation team members also affect the success of EBIs in schools. Common individual-level barriers include varying levels of experience and expertise, perceptions of and attitudes towards interventions, and clinical responsivity and flexibility (Domitrovich et al., 2008; Eiraldi et al., 2015). Outer setting barriers, which include economic, political, and social contexts of organizations, are often unique to the state or community within which the school exists. For instance, many school systems face funding cuts leading to sequelae such as limited space and materials, reduced availability of mental health professionals, and 
individuals employed to serve multiple roles (Forman et al., 2009; Markle et al., 2014; Thaker et al., 2008). Finally, intervention characteristics, such as expert-level or esoteric treatment materials, can hinder the implementation of EBIs in schools. Previous research has found that school-based therapists report difficulty with training and treatment materials, including trouble gaining familiarity with the material and subsequently using the intervention (Langley et al., 2010). One study of the sustainability of a CBT program in schools suggested that implementation efforts that aim to lower administrative demands and include interventions that are easy to administer with clear benefits may help overcome barriers in the school setting (LoCurto et al., 2020)

Technology has been proposed as a strategy to reduce implementation burden of EBI in schools. Computer administered programs have been shown to be an effective medium through which to disseminate EBIs for youth anxiety disorders and obsessive compulsive disorder (e.g., Comer et al., 2017; Khanna et al., 2014; Khanna \& Kendall, 2008; Sarver et al., 2014). In computer-assisted programs, the EBI is run on the computer with the help of a coach (Khanna et al., 2014). Computer-assisted treatments offer many benefits including: (1) decreasing the expertise level necessary for implementation; (2) reducing treatment cost and the subsequent financial burden on the school by limiting necessary one-on-one time with a provider (Carroll \& Rounsaville, 2010; McCrone et al., 2004; Newman, 2000; Wright et al., 2005); and (3) potentially increasing treatment fidelity, standardization, and client adherence (Khanna \& Kendall, 2010). Altogether, a computerized format may aid in mitigating many of the common barriers to the successful implementation of EBIs in school settings.

Camp Cope-A-Lot (CCAL; Khanna \& Kendall, 2008) is a 12-session computer-assisted treatment program based on Coping Cat (Kendall \& Hedtke, 2006) that was developed to treat youth ages 7 to 13 years with generalized anxiety disorder, social anxiety disorder, and separation anxiety disorder. Results of an initial randomized clinical trial indicated that CCAL was an acceptable treatment to parents and children, feasible to implement by treatment providers with minimal CBT experience, and with no training in CCAL (Khanna \& Kendall, 2010). Further, CCAL demonstrated comparable efficacy in anxiety symptom reduction when compared to face-to-face CBT. In a separate pilot study, therapists from community mental health centers received a two-day training on CCAL, followed by weekly group supervision (Crawford et al., 2013). This study also suggested that CCAL resulted in significant reductions in anxiety symptoms and high levels of client satisfaction. Although computer assisted programs like CCAL have the potential to be implemented by lay mental health providers, whether such providers are able to implement the program successfully has yet to be examined. Furthermore, 
research has not examined the feasibility of implementing a computer-assisted intervention for anxiety in a school setting.

This study evaluates the 5-year Coping At Schools and Dissemination Of Good Strategies (CATS and DOGS) study. The CATS and DOGS study investigated the implementation and sustainability of a computerassisted CBT program (CCAL), which was provided to anxious youth in first through fourth grade by both school mental health staff and lay professionals. The current examination uses the CFIR framework to characterize facilitators and barriers resulting from the CCAL implementation in schools. In doing so, we explore whether a computer-based intervention, which was designed to reduce barriers to implementation, mitigates many common barriers to implementing EBIs in school settings. Furthermore, we examine how implementation determinants affect the implementation of this computer-assisted program by school mental health staff and lay professionals.

\section{Method}

\section{Participants}

Participants were school personnel who were trained to provide CCAL as part of an implementation study (CATS and DOGS). The current sample includes interviews obtained from 45 providers (five providers had two interviews selected-one at each time-point). Demographic characteristics are presented in Table 1. Providers were primarily female $(84 \%)$, White $(91 \%)$, middle-aged $(M=42.56, S D=10.98)$, and school mental health workers (62\%). Providers reported a variety of theoretical orientations and around half reported previous experience treating anxiety.

\section{Intervention}

As described above, CCAL (Kendall \& Khanna, 2008a) is a 12-session computer-assisted treatment program for child anxiety (for a more detailed description of CCAL, see Khanna \& Kendall, 2008). The first six sessions are implemented by the computer program, and include relaxation training, cognitive restructuring, and problem solving skills. Rather than simply being didactic, CCAL is set up as a sleepaway camp. Children learn about anxiety by discussing situations that may occur at camp. Charlie and other characters in the program demonstrate the coping skills and provide prompts as feedback to the client's responses. The second six sessions include exposure tasks, which are conducted by the provider. The exposure tasks are customized to each client. Providers receive a paper copy of the Coach's Manual (Kendall \& Khanna, 2008b), which describes the rational for each treatment component. Youth receive the Go-to-Gadget workbook (Kendall \& Khanna, 2008c) to complete 
homework tasks; this workbook includes a brief session summary, as well as the homework worksheet. This project used a CD-ROM version of CCAL. Since the project took place, an online version of CCAL has been made available. Paper copies of the provider and client workbook still are used in this online version. CCAL is advertised as being able to be used by providers without formal training in CBT.

\section{Procedure}

CATS and DOGS used a cohort-sequential design, such that the project consisted of three consecutive annual waves of school enrollment, with each school participating in the project for a total of three years. Participants were recruited at the school level; there were 29 schools enrolled across the three study waves: (1) Wave 1 included 9 suburban schools across several districts outside the Philadelphia, PA USA metropolitan area, (2) Wave 2 included 7 schools across several districts in roughly the same suburban area, and (3) Wave 3 included 13 schools in one district in a suburb in the Toronto, ON, Canada metropolitan area. Different recruitment approaches were adopted for each of the three study waves due to the project's use of a feedback-loop, based on Fixsen et al.'s (2005) model. Recruitment models included a top-down approach in Wave 1 (i.e., contacting previous collaborators, who then facilitated informational meetings with school principals), a bottom-up approach in Wave 2 (i.e., outreach presentations to schools led by study staff), and a mixed approach in Wave 3.

Study participation began in the winter of Year 1, when CCAL service providers $(N=74)$ completed a oneday didactic training workshop on the CCAL program. Providers then implemented the 12-week CCAL program for eligible youth in spring of Year 1. For three months following training, weekly hour-long group consultation calls led by master's and doctoral level clinicians with training and experience in the treatment of youth anxiety were offered to support the delivery of CCAL. Consultation activities included conducting behavioral rehearsals (role plays), troubleshooting problems, and generating ideas for exposures. Referrals for youth to participate in CCAL were provided using the Behavior Assessment System for Children-II (BASC; Reynolds \& Kamphaus, 2002), and via teacher/guidance counselor nominations. Despite its length (139 items), the BASC was selected based on feedback from school stakeholders, who liked the BASC because it is frequently used in schools. Youth referred using the BASC were eligible for CCAL if their t-score on the anxiety subscale was greater or equal to 60 . During Years 2 and 3 (Sustainability Phase), minimal additional supports (i.e., one sustainability meeting per year) were provided to examine the sustainability of service providers' use of CCAL. Schools were recruited between 2011 and 2013; study participation for all schools was completed by 2016 . 


\section{Interview Procedure}

All procedures were approved by the Temple University Institutional Review Board. All participants were contacted to participate in qualitative interviews at the end of Year 1 (Implementation Phase), Year 2 (Sustainability Phase), and Year 3 (Sustainability Phase). See Figure 1 for the participant flow. Due to low response rates at Year 3 (due to staff turnover and participant attrition), only Year 1 (Implementation) and Year 2 (Sustainability) interviews were coded. Interviews were completed in approximately 20 minutes via phone and were digitally recorded. Interviewers consisted of two White male and three White female master's level clinicians with specialized training and experience treating child anxiety. The interviewers had no prior relationship with the participants, although some participants may have met the interviewer when the interviewer distributed or collected questionnaire packets. Participants were told that the interview was being conducted to understand barriers and facilitators to implementation. If allowed by their school districts, participants were compensated for their overall participation in the CATS and DOGS study, but participants were not compensated specifically for participating in the qualitative interviews.

Interview questions followed a revised version of the Evidence Based Developer Interview (EBDI; Forman et al., 2009), a semi-structured qualitative interview on facilitators and barriers to provider program implementation and sustainability. For the implementation phase, question content covered six aspects of implementation: (1) general information (e.g., "Describe how your thoughts about CBT in general changed through your involvement in this project." and "What do you think are the most helpful aspects of Camp Cope-A-Lot? The least?"), (2) the school context (e.g., "What have been the major obstacles or hindrances that you have encountered?"), (3) individuals involved (i.e., teachers, administrators, school special services staff, parents, students, outside agencies), (4) projected program sustainability (e.g., "Are you likely to continue using the program?”), (5) consultation calls (e.g., "What was least helpful about consultation?"), and (6) using the BASC to identify anxious youth (e.g., "Did you encounter any major obstacles or hindrances in administering the BASCs?"). For the sustainability phase, questions elicited information on the role of the school context, individuals involved, and staff turnover in the sustainable implementation of CCAL. The qualitative interview questions and data analysis codebook are available from the authors upon request.

\section{Qualitative Coding and Data Analysis}


Qualitative interviews were audio recorded, and interviews were transcribed and checked by undergraduate research assistants. A subset of interviews was randomly selected and coded until saturation was reached (25/50 Year 1 interviews were coded; 25/38 Year 2 interviews were coded). A priori codes, which were selected based on the EBDI, included training/consultation, sustainability, champions, referral process, treatment materials, modifications, school organization factors, external factors, administrators, teachers, mental health staff, other school staff, CBT attitudes, and client/parents. Interviews were analyzed in an iterative process to generate the codes (Hill et al., 1997). Using the codebook and qualitative software QSR NVivo 12, text segments were coded into the fourteen thematic nodes, a barrier node, and a facilitator node. Two raters (JB, SS) were trained by the first author (MC) until they had at least $90 \%$ agreement with the first author on each code. These two raters then independently coded a randomly selected subset of 25 interviews from both the initial implementation and sustainability phases (50 interviews total), while meeting with the first author to resolve any discrepancies and ensure consensus. Rating consensus between the two raters was calculated on a random subset of $20 \%$ of interviews that were double coded; kappa $=.82$ across all codes (excellent agreement; DeSantis \& Ugarriza, 2000; Hill et al., 2005).

We used a thematic template qualitative analytic approach (Brooks et al., 2015). This approach allows for data to be thematically organized using a pre-existing theoretical framework (in this case, CFIR). Thematic analysis proceeded in an iterative process using three coders (MC, KP, HF). Using NVivo software, each of the fourteen nodes were sorted by the facilitators and barriers nodes, and by the implementation and sustainability phases, thus producing four sections (i.e., facilitators, implementation; facilitators, sustainability; barriers implementation; barriers, sustainability) for each of the fourteen nodes. When analyzing the fourteen nodes, the CFIR framework was used to conceptualize the qualitative codes given the amount of overlap between the EBDI and CFIR framework (Damschroder et al., 2009); a priori codes from the EBDI were reorganized according to the CFIR domain to which they corresponded. The following codes were collapsed into conceptually similar categories: modifications (collapsed into treatment materials), external factors (collapsed into school organizational factors), other school staff (collapsed into administration), and sustainability (redundant with sorting the codes by implementation and sustainability phases). Training/consultation and child/parent codes were each split into two themes (i.e., training, consultation, child, and parent). Although the nodes were coded by initial implementation and sustainability, themes were collapsed across timepoints when the theme was referenced in both time points. Thematic coding was conducted in Microsoft Excel consistent with guidelines set by Meyer and Avery (2009). Coders noted themes for 
each of the four sections (facilitators, implementation; facilitators, sustainability; barriers implementation; barriers, sustainability) for each node. In line with qualitative research, which is not based on counting or quantifying material (Morse, 2007; Strauss \& Corbin, 1998), frequencies of themes were not calculated. Participants did not provide feedback on the transcripts or qualitative findings.

\section{Results}

The majority of providers $(91.1 \%)$ treated at least one anxious youth during the implementation stage. Providers who treated a child treated on average between one and two anxious youth $(M=1.67, S D=1.01)$ and attended approximately five (of 12$)$ consultation calls $(M=5.47, S D=3.42)$. Youth were predominately male $(62 \%)$ and white $(70 \%)$, and were an average age of 8.38 years $(S D=1.22)$. See Table 2 for a summary of themes and selected quotes to offer examples of recurrent ideas from the interviews.

\section{Implementation Process}

\section{Training}

Facilitators. In the implementation phase, participants reported that they found the training to be helpful. In particular, participants stated that learning a manualized CBT program allowed them to learn specific techniques they may use in isolation from the full program.

Barriers. However, participants also indicated that they would have appreciated more information on exposures, including how to create a hierarchy and how to implement exposures for anxiety that may not be present at school. In both the implementation and sustainability phases, a few participants recommended that all school staff members attend the trainings to gain a broad understanding of EBIs for anxiety.

\section{Consultation}

Facilitators. In the implementation phase, participants reported that consultation calls were a helpful aspect of training. Many participants described appreciating consultants' interpersonal skills: the consultants were friendly, created an environment open to questions, and were readily available to answer questions outside of consultation calls. Participants reported that the content of the calls helped to reinforce what was learned in training, preview what was ahead in the program, facilitate understanding of how to adapt the program to specific clients, generate exposure ideas, and provide opportunities to practice skills via role plays. Consultation calls also provided participants with an opportunity to receive technical support. Participants' opinions of having group consultation 
varied; some found it helpful to hear others' experiences, while others felt that others' issues were irrelevant and took up too much time. Most participants reported that the flexible timing of consultation calls was important.

Barriers. Participants also reported that time was a barrier to attending the calls. They stated that it was difficult to find a time for the call and to stick to the scheduled time when other tasks arose. Many participants reported that the calls were too long (1 hour) and too frequent (weekly), and they suggested that the calls should be scheduled as needed. Finally, a few participants reported technology issues with the consultation calls (e.g., being unfamiliar with the video software, having connection difficulties). No additional consultation sub-themes emerged in the sustainability phase.

\section{Champions}

Facilitators. In both the implementation and sustainability phases, participants identified program champions in a variety of roles, including school principal, superintendent, assistant superintendent, teacher, special education director, speech therapist, guidance counselor, school psychologist, lead mental health staff member, and support staff. Champions facilitated the program by believing the program would work, creating positive publicity to promote the program, changing schedules to allow providers and clients to use the program, encouraging sustained use of the program, and using relationships to overcome implementation barriers.

Barriers. Participants described champion staff turnover as a barrier to sustained implementation.

\section{Intervention Characteristics}

Facilitators. In both the implementation and sustainability phases, participants reported that they found CCAL to be highly acceptable and understandable to the youth clients. They described the following characteristics as being particularly kid-friendly and engaging: interactive practice; games/rewards; and cartoon videos that describe the concept, provide examples, and model behavior. Participants stated that they found the program to be effective, and that they liked that it focused on coping skills (e.g., relaxation, thinking traps, problem solving). In general, participants found the computer-based program to be easy to administer, and they appreciated having a paper therapist manual and workbook as a supplement. Additionally, they thought that the program had a logical order and was well organized.

Barriers. Technical aspects of the program were the most frequently described program-related barrier to implementation. Many participants reported technology problems with the computer program working, and some stated that they would have preferred to be able to have multiple children using the program at once, which was not 
possible because the CD-ROM only allowed one computer to use the program at a time. Furthermore, although CCAL was designed to be computer-assisted, many providers referenced going through the entire program with the client, rather than having the client work independently through the first half of the program. Additionally, some participants reported that the program felt repetitive at the end; however, it was unclear if this was specific to the animations in CCAL or if they felt that exposures in general were repetitive. They noted that they felt unclear about how to flexibly use the program (e.g., selectively choosing skills when the client does not need the entire manualized program). Finally, some participants stated that the program relied too heavily on the assumption that clients would complete the homework assignments.

\section{Inner Setting}

\section{School Organizational Factors}

Facilitators. In both the implementation and sustainability phases, school culture and organizational structures emerged as both facilitators and barriers to CCAL implementation. Having a culture of support and willingness to try new things emerged as a facilitator. School structures that enabled the child to be pulled out of class were also a facilitator. Some participants noted that it was helpful to have a designated time for CCAL sessions, while others noted that they appreciated having flexibility in scheduling. Participants also reported that existing mental health initiatives in the school facilitated implementing a new program. In the sustainability phase, participants noted that CCAL was more likely to continue to be used when people in the school were familiar with the program (i.e., how the program works, who implements the program).

Barriers. Almost all participants noted that it was difficult to find time to complete the program, both due to school culture and structural factors. Some participants reported that education was a priority for the school (including preparing for standardized tests), and schools did not always prioritize socioemotional learning. Other participants described that the only time to pull a child out of class was during the special classes (e.g., art, music). In addition, special events, field trips, and other programs made scheduling difficult. Almost all participants felt that the program was too long to be implemented in a school setting, in terms of both session length (45 minutes) and number of sessions (12). In the sustainability phase, there were many reports of turnover among teachers and school mental health staff. Although some participants reported that they managed staff turnover by training new staff in the program — even though this was not a formal part of the implementation initiative—others reported instances in 
which staff turnover led to the program being discontinued. Many participants also reported that it was difficult to continue implementing CCAL if conducting psychological interventions was not their primary role in the school.

\section{Referral Process}

Facilitators. In both the implementation and sustainability phases, many participants stated that identification of anxious youth was a key facilitator of CCAL use because it highlighted the need for the program. They noted that parent and teacher willingness to complete questionnaires to identify anxious youth, as well as teacher and mental health staff referrals, were helpful. Some participants felt that as teachers gained awareness of anxiety and viewed the CCAL provider as an anxiety expert, they were more likely to provide referrals and ask the provider questions. Furthermore, they noted that this referral process helped build the relationship between teachers and providers.

Barriers. A poor referral process emerged as a barrier to CCAL use. Many participants noted that the BASC was not an ideal screening tool due to the length of time it took to complete. Some participants identified a lack of communication about what the BASC is and why teachers should complete it. Insufficient referrals also emerged as a barrier to sustained CCAL use. In the sustainability phase, participants described that this lack of referrals may have been due to a lack of program awareness from school staff (e.g., teachers), or due to poor communication after staff identified anxious youth.

\section{Characteristics of Individuals Involved}

\section{Administration}

Facilitators. A number of specific administrative actions and attitudes emerged as facilitators to CCAL implementation in both the implementation and sustainability phases. At some schools, administrators were a core part of the implementation team; they initiated the program implementation, coordinated the program, and disseminated information about the implementation of the BASC and CCAL. Some administrators also were involved in the referral and treatment processes, providing CCAL providers with referrals and checking-in on client progress. The role of administrators as gatekeepers for designating staff time was an overarching theme. Administrators facilitated implementation when they provided time for providers to attend the training and to conduct CCAL sessions, for teachers to complete the BASC (including providing substitute teachers), and for students to be out of the classroom. Many participants also described how administrators made resources available for providers to complete CCAL, including computers, rooms, and on-site technical support. Conversely, some 
participants noted that administrators facilitated implementation by being "hands off" (i.e., allowing staff to implement the program independently). Participants frequently noted how positive administrator attitudes supported CCAL implementation, such as seeing anxiety as an important treatment target and being willing to try new things.

Barriers. Broader administrative actions and attitudes emerged as barriers to initial and sustained CCAL implementation. Participants noted that a lack of clear communication about CCAL and the BASC was a barrier to implementation. At some schools, administrators wanted the CCAL providers to focus their time on other tasks. This problem seemed to be exacerbated in the sustainability phase; a number of participants noted that administrators did not support the shift in school staff responsibility that would be necessary for non-mental health staff members to continue using CCAL.

\section{Teachers}

Facilitators. Two themes emerged relating to teachers' roles in CCAL implementation (in both the implementation and sustainability phases): scheduling and teachers' involvement in the treatment process. Many participants stated that teachers allowed for the child to be pulled out of their classroom - some even walked the child to the CCAL session. Participants reported that teachers facilitated CCAL implementation by being involved with the treatment process including (a) giving providers information about a child's anxiety, (b) communicating with providers about progress, (c) helping the child practice skills learned in CCAL, and (d) participating in exposures.

Barriers. Some participants stated that teachers were "protective" over students' time in their classrooms. Additionally, some teacher providers had difficulty scheduling time to facilitate CCAL sessions.

\section{Mental Health Staff}

Facilitators. In both the implementation and sustainability phases, participants reported many instances in which the school mental health staff facilitated implementation, including pushing for the program to be implemented and coordinating the program implementation (e.g., facilitating communication with teachers). Mental health staff also described doing peer consultation with each other to generate exposure ideas and troubleshoot difficulties. Peer consultation was something they set up independently; it was not a formal part of the implementation process. They also reported instances in which they coordinated care with an outside therapist. Finally, the theme of being willing to try a new program also emerged as a facilitator related to mental health staff. 
Barriers. Participants also reported a number of barriers associated with the structure of their job description. In some cases, mental health staff stated that their role was psychological testing, and they did not have time to conduct interventions. In other cases, mental health staff described having many responsibilities and competing demands (e.g., bullying prevention, individualized education plan meetings). Even when they were able to schedule sessions, they reported that sessions often would be interrupted by a "crisis situation" that they were required to manage. Furthermore, some participants stated that their schedules were irregular and/or they were not at the school every day, which made it difficult to schedule with the client.

\section{CBT Attitudes}

Facilitators. In the implementation phase, many participants reported that by implementing a CBT program, they gained a positive view of CBT, regardless of their previous view. Participants who self-described as having negative views about CBT prior to implementation reported that their view improved when they saw that the program worked and could be individualized to each child. They reported that they found relaxation skills, coping thoughts, and exposures to be particularly helpful. Most participants described exposures as the "most helpful" part of the program.

Barriers. When asked about whether they would make modifications to the program, many participants reported that they would use individual components, rather than the full program, in the future. Although many participants stated that they found it useful to build an exposure hierarchy, some felt that the hierarchy had "too many options." Additionally, some stated that exposures were not useful when the child's anxiety was not something that occurred at school.

\section{Outer Setting Factors}

\section{Child Clients}

Facilitator. Child engagement in CCAL was a facilitator to program use in both the implementation and sustainability phases. Impressively, almost every participant noted that the children were engaged in the program and were willing to participate in it. Participants reported that they believed the program was best for children in second through fourth grade, and overall, the children liked the cartoons.

Barriers. Participants mentioned a few instances in which client characteristics and/or actions made program implementation harder. For example, some participants noted that the materials were not in the right age range, with the cartoons feeling "young" for older clients and the content being too complicated for children in 
kindergarten or first grade. They described a few instances in which socioemotional problems interfered with the program, including behavioral problems that made it hard for the child to focus, difficulty with less verbal children, and a few instances in which they felt the child was "too anxious" to engage in the program, especially the exposures. Finally, child absences made it difficult to complete the program.

\section{Parents}

Facilitators. A number of parent actions were identified as facilitators to program implementation in the implementation phase. No additional parent actions were reported in the sustainability phase. Facilitators included parents returning forms, granting permission to complete the program, and generally being supportive of the program.

Barriers. The majority of barriers were the opposite of these facilitators. Some parents did not want their child to complete the program, either because they did not want their child missing class or because they did not want their child participating in therapy. A number of providers described that it was difficult to complete CCAL because parents did not help their child complete their therapy homework. Participants found it difficult to schedule time to communicate with parents.

\section{Discussion}

This study is the first to qualitatively examine multi-level determinants of the implementation of a computer-assisted anxiety intervention in schools. The rich contextual information yielded by the qualitative approach contributes to a greater understanding of the complex relationships among determinants in school-based mental health care delivery. Our findings highlight several potential points of intervention that can be used to inform the design of implementation strategies for future school-based implementation efforts. Results suggest that the computer-assisted intervention, which was designed to be delivered by lay mental health workers, did not fully mitigate resource-related barriers to implementation (e.g., limitations of time and competing demands; Forman et al., 2009). Despite this, the intervention was well-liked by children and providers, as has been found in previous work (Khanna \& Kendall, 2008; Khanna \& Kendall, 2010).

Competing demands on providers' time remained the foremost barrier to implementation, despite the use of a computer-assisted program, raising a question about the added utility of computer-assisted interventions in the school setting. Although the amount of time spent with individual students was not recorded, the CCAL did not appear to reduce one-on-one time between students and providers to the degree necessary for ameliorating provider 
concerns about competing demands. A future investigation comparing the amount of time spent by providers delivering computer-assisted and non-computer-assisted interventions would be helpful in elucidating the extent to which this intervention characteristic (i.e., computer-assisted) can be expected to address time constraints. Given that CCAL is now available online, future studies could examine having the youth complete online modules as homework before the session so that session time could be used to discuss material and conduct exposures.

Although the use of a computer-assisted intervention did not altogether address the barrier of competing demands, results indicate that organizational factors such as administrative support likely affected the implementation process and outcomes, as is commonly found across settings and interventions (Durlak \& DuPre, 2008). Our results underscore the importance of engaging administration and leadership, given that they serve as the central gatekeepers in school organizational settings and can determine whether mental health treatment is prioritized in the school. Specifically, our findings illustrate that coordinating mental health intervention services in schools requires a high degree of flexibility in scheduling, echoing those of several prior studies (Zenner \& Walach, 2014). Thus, administrators that impose strict rules about scheduling may reinforce this barrier to implementation. Conversely, administrators can help minimize this barrier by actively coordinating and designating time for treatment or by passively allowing schedules to shift as care is coordinated by others. These findings suggest that the use of strategies by school leadership to grant providers greater flexibility may be beneficial to future implementation efforts, and are consistent with research indicating that greater autonomy in the execution of daily tasks is associated with greater performance by service providers (Olin et al., 2014). Additionally, our findings support previous literature suggesting that for task-shifting to be a sustainable implementation strategy, staff members' job duties require restructuring to allow them to continue to implement the program (World Health Organization, 2008). Future research examining strategies for engaging school administrations would benefit from the use of measures of organizational factors, such as leadership and climate, that are adapted for schools (Lyon \& Bruns, 2019) and quantitatively assess the factors' influence on implementation outcomes.

Participants identified the time burden of the intervention and the assessment as barriers to implementation. Concerns about intervention timing were related to session length and the number of sessions required to complete the program. This points to a lack of fit between the intervention and setting, underscoring the need to adapt intervention designs to match the school context (Lyon \& Bruns, 2019). School-based interventions do not typically follow the same structure as outpatient services (i.e., weekly, 45-minute sessions; Beidas et al., 2012; Benjamin et 
al., 2014). Even though CCAL was designed to minimize provider burden, the fact that it still required 45 -minute sessions likely hindered the utility of the program. Critiques of the number of sessions indicate that shorter interventions, perhaps even single session interventions, may be a better format to implement EBIs in school settings (Schleider et al., 2019). Furthermore, many participants commented on the onerous nature of the BASC. Shorter screening measures (e.g., the Patient-Reported Outcomes Measurement Information System-anxiety scale; Pilkonis et al., 2011) would likely be more feasible for teachers (Becker-Haimes et al., 2019). User-centered design strategies also may be helpful for creating/adapting EBIs to fit school contexts (Lyon \& Koerner, 2016).

Despite these shortcomings, the intervention allowed school personnel without specialty mental health backgrounds to deliver the anxiety-focused treatment to students. A strength of computer-based interventions is that they reduce the expertise and training required to deliver high-quality treatment (Carroll \& Rounsaville, 2010; Wright et al., 2005). Our results support this strength, particularly for the didactic portion of the program. In line with previous research that examined task-shifting with school nurses (Ginsburg et al., 2019; Stallard et al., 2007), our findings support the potential for lay mental health workers to be trained to implement EBIs. However, CCAL providers expressed difficulty conducting exposures, and they expressed a desire for greater training (both peer and external consultation) in personalizing exposures for each client. This is an important caveat, given that exposure is considered a critical active ingredient in EBIs for anxiety (Whiteside et al., 2020). Notably, this pattern of selective use of protocol components is not unique to the school setting. For example, Chu et al. (2015) found that 3-4 years after being training in CBT, providers were more likely to use emotion education, relaxation, problem-solving, and rewards, and were less likely to use exposures and homework. This suggests that relative to other intervention techniques, sufficient exposure use likely requires more training and support than is currently afforded to school providers. Our findings are in contrast to previous quantitative research, which found that therapists with limited training in CBT and no training in CCAL were able to implement CCAL effectively (Khanna \& Kendall, 2010). It is possible that although providers may be able to implement CCAL with minimal training (Khanna \& Kendall, 2010), training may be required to increase provider self-efficacy for exposure techniques.

There are several limitations. First, despite the methodological utility of the three-wave design using different recruitment strategies, this variability presents challenges: we did not systematically evaluate the different recruitment strategies. Second, due to the nature of the recruitment process, schools that opted to participate may have systematically differed from those who opted not to participate. Third, the majority of clients treated by 
providers in this sample were White. The cultural relevancy of CCAL to clients from other racial/ethnic groups is unclear. Furthermore, many providers did not report demographic information for their clients, which further limits our ability to interpret the generalizability of the findings. Fourth, the version of CCAL program that was available at that time had technology glitches (e.g., did not work on some computers). It is unclear whether some barriers to implementation related to the CCAL program (e.g., technology problems) were specific to the CCAL program, or whether these barriers may generalize to other computer-assisted treatments.

Despite these limitations, this qualitative investigation of the utility of computer-based interventions in schools provides insights for several promising directions for future research. Overall, none of the barriers that were identified by the current study negate the potential advantages of employing computer-based interventions or lay mental health workers to support the implementation of a school-based mental health intervention. Rather, findings suggest that (1) harnessing the full potential of a computer-assisted delivery method may require a set of specific implementation strategies tailored to the school setting, and (2) lay mental health workers may still prove vital to the effective delivery of school-based interventions, particularly when provided adequate infrastructure and support. Insights gleaned from this investigation offer guidance for future work on how to maximize the benefits of these delivery methods to more effectively address youth mental health treatment needs in schools. 


\section{References}

Allensworth, D., Lawson, E., Nicholson, L., \& Wyche, J. (1997). Schools \& Health: Our Nation's Investment. National Academies Press (US). https://doi.org/10.17226/5153

Atkins, M. S., Cappella, E., Shernoff, E. S., Mehta, T. G., \& Gustafson, E. L. (2017). Schooling and children's mental health: Realigning resources to reduce disparities and advance public health. Annual Review of Clinical Psychology, 13, 123-147. https://doi.org/10.1146/annurev-clinpsy-032816-045234

Barrett, P., \& Turner, C. (2001). Prevention of anxiety symptoms in primary school children: Preliminary results from a universal school-based trial. British Journal of Clinical Psychology, 40, 399-410. https://doi.org/10.1348/014466501163887

Becker-Haimes, E. M., Tabachnick, A. R., Last, B. S., Stewart, R. E., Hasan-Granier, A., \& Beidas, R. S. (2019). Evidence Base Update for Brief, Free, and Accessible Youth Mental Health Measures. Journal of Clinical Child and Adolescent Psychology, 49(1), 1-17. http://doi.org/10.1080/15374416.2019.1689824

Beidas, R. S., Edmunds, J. M., Marcus, S. C., \& Kendall, P. C. (2012). Training and consultation to promote implementation of an empirically supported treatment: A randomized trial. Psychiatric Services, 63, 660665. https://doi.org/10.1176/appi.ps.201100401

Benjamin, C. L., Taylor, K. P., Goodin, S. M., \& Creed, T. A. (2014). Dissemination and implementation of cognitive therapy for depression in schools. In R. S. Beidas \& P. C. Kendall (Eds.), Dissemination and implementation of evidence-based practices in child and adolescent mental health (pp. 277-293). Oxford University Press.

Brooks, J., McCluskey, S., Turley, E., \& King, N. (2014). The Utility of Template Analysis in Qualitative Psychology Research. Qualitative Research in Psychology, 12(2), 202-222. https://doi.org/10.1080/14780887.2014.955224

Carroll, K. M., \& Rounsaville, B. J. (2010). Computer-assisted therapy in psychiatry: Be brave-It's a new world. Current Psychiatry Reports, 12, 426-432. http://doi.org/10.1007/s11920-010-0146-2

Chu, B. C., Talbott Crocco, S., Arnold, C. C., Brown, R., Southam-Gerow, M. A., \& Weisz, J. R. (2015). Sustained implementation of cognitive-behavioral therapy for youth anxiety and depression: Long-term effects of structured training and consultation on therapist practice in the field. Professional Psychology: Research and Practice, 46, 70-79. https://doi.org/10.1037/a0038000 
Comer, J. S., Furr, J. M., Miguel, E. M., Cooper-Vince, C. E., Carpenter, A. L., Elkins, R. M., Kerns, C. E., Cornacchio, D., Chou, T., Coxe, S., DeSerisy, M., Sanchez, A. L., Golik, A., Martin, J., Myers, K. M., \& Chase, R. (2017). Remotely delivering real-time parent training to the home: An initial randomized trial of Internet-delivered parent-child interaction therapy (I-PCIT). Journal of Consulting and Clinical Psychology, 85, 909-917. https://doi.org/10.1037/ccp0000230

Cooper, J. L. (2008). The federal case for school-based mental health services and supports. Journal of the American Academy of Child and Adolescent Psychiatry, 47, 4-8. https://doi.org/10.1097/chi.0b013e31815aac71

Costello, E. J., Mustillo, S., Erkanli, A., Keeler, G., \& Angold, A. (2003). Prevalence and development of psychiatric disorders in childhood and adolescence. Archives of General Psychiatry, 60, 837-844. https://doi.org/10.1001/archpsyc.60.8.837

Crawford, E. A., Salloum, A., Lewin, A. B., Andel, R., Murphy, T. K., \& Storch, E. A. (2013). A pilot study of computer-assisted cognitive behavioral therapy for childhood anxiety in community mental health centers. Journal of Cognitive Psychotherapy, 27, 221-234. https://doi.org/10.1891/0889-8391.27.3.221

Damschroder, L. J., Aron, D. C., Keith, R. E., Kirsh, S. R., Alexander, J. A., \& Lowery, J. C. (2009). Fostering implementation of health services research findings into practice: A consolidated framework for advancing implementation science. Implementation Science, 4, 50. https://doi.org/10.1186/1748-5908-4-50

DeSantis, L., \& Ugarriza, D. N. (2000). The concept of theme as used in qualitative nursing research. Western Journal of Nursing Research, 22, 351-372. https://doi.org/10.1177/01939450022044467

Domitrovich, C. E., Bradshaw, C. P., Poduska, J. M., Hoagwood, K., Buckley, J. A., Olin, S., Romanelli, L. H., Leaf, P. J., Greenberg, M. T., \& Ialongo, N. S. (2008). Maximizing the implementation quality of evidencebased preventive interventions in schools: A conceptual framework. Advances in School Mental Health Promotion, 1, 6-28. https://doi.org/10.1080/1754730X.2008.9715730

Durlak, J. A., \& DuPre, E. P. (2008). Implementation matters: A review of research on the influence of implementation on program outcomes and the factors affecting implementation. American Journal of Community Psychology, 41, 327. https://doi.org/10.1007/s10464-008-9165-0

Eiraldi, R., Wolk, C. B., Locke, J., \& Beidas, R. (2015). Clearing hurdles: the challenges of implementation of mental health evidence-based practices in under-resourced schools. Advances in School Mental Health Promotion, 8, 124-140. https://doi.org/10.1080/1754730X.2015.1037848 
Farmer, E. M., Burns, B. J., Phillips, S. D., Angold, A., \& Costello, E. J. (2003). Pathways into and through mental health services for children and adolescents. Psychiatric Services, 54, 60-66. https://doi.org/10.1176/appi.ps.54.1.60

Fiscella, K., \& Kitzman, H. (2009). Disparities in academic achievement and health: The intersection of child education and health policy. Pediatrics, 123, 1073-1080. https://doi.org/10.1542/peds.2008-0533

Fixsen, D. L., Naoom, S. F., Blase, K.A., Friedman, R. M., \& Wallace, F. (2005). Implementation research: A synthesis of the literature. University of South Florida, Louis de la Parte Florida Mental Health Institute, The National Implementation Research Network (FMHI Publication \#231).

Forman, S. G., Olin, S. S., Hoagwood, K. E., Crowe, M., \& Saka, N. (2009). Evidence-based interventions in schools: Developers' views of implementation barriers and facilitators. School Mental Health, 1, 26. https://doi.org/10.1007/s12310-008-9002-5

Franklin, C. G., Kim, J. S., Ryan, T. N., Kelly, M. S., \& Montgomery, K. L. (2012). Teacher involvement in school mental health interventions: A systematic review. Children and Youth Services Review, 34, 973-982. https://doi.org/10.1016/j.childyouth.2012.01.027

Ginsburg, G. S., Drake, K. L., Muggeo, M. A., Stewart, C. E., Pikulski, P. J., Zheng, D., \& Harel, O. (2019). A pilot RCT of a school nurse delivered intervention to reduce student anxiety. Journal of Clinical Child \& Adolescent Psychology, 1-10. https://doi.org/10.1080/15374416.2019.1630833

Hazen, A. L., Hough, R. L., Landsverk, J. A., \& Wood, P. A. (2004). Use of mental health services by youths in public sectors of care. Mental Health Services Research, 6, 213-226. https://doi.org/10.1023/B:MHSR.0000044747.54525.36

Hill, C. E., Knox, S., Thompson, B. J., Williams, E. N., Hess, S. A., \& Ladany, N. (2005). Consensual qualitative research: An update. Journal of Counseling Psychology, 52, 196-205. https://doi.org/10.1037/00220167.52.2.196

Hill, C. E., Thompson, B. J., \& Williams, E. N. (1997). A guide to conducting consensual qualitative research. The Counseling Psychologist, 25, 517-572. https://doi.org/10.1177/0011000097254001

Hollon, S. D., \& Beck, A. T. (2013). Cognitive and cognitive-behavioral therapies. In Bergin and Garfield's handbook of psychotherapy and behavior change (Vol. 6, pp. 393-442). Wiley. 
Hudson, K. G., Lawton, R., \& Hugh-Jones, S. (2020). Factors affecting the implementation of a whole school mindfulness program: A qualitative study using the consolidated framework for implementation research. BMC Health Services Research, 20, 133. https://doi.org/10.1186/s12913-020-4942-z

Husky, M. M., Sheridan, M., McGuire, L., \& Olfson, M. (2011). Mental health screening and follow-up care in public high schools. Journal of the American Academy of Child \& Adolescent Psychiatry, 50, 881-891. https://doi.org/10.1016/j.jaac.2011.05.013

Kataoka, S., Stein, B. D., Nadeem, E., \& Wong, M. (2007). Who gets care? Mental health service use following a school-based suicide prevention program. Journal of the American Academy of Child and Adolescent Psychiatry, 46, 1341-1348. https://doi.org/10.1097/chi.0b013e31813761fd

Kataoka, S. H., Zhang, L., \& Wells, K. B. (2002). Unmet need for mental health care among US children: Variation by ethnicity and insurance status. American Journal of Psychiatry, 159, 1548-1555. https://doi.org/10.1176/appi.ajp.159.9.1548

Kendall, P. C., \& Hedtke, K. A. (2006). Cognitive-behavioral therapy for anxious children: Therapist manual. Workbook Publishing.

Kendall, P. C., Hudson, J., Gosch, E., Flannery-Schroeder, E., \& Suveg, C. (2008). Cognitive-behavioral therapy for anxiety disordered youth: A randomized clinical trial evaluating child and family modalities. Journal of Consulting and Clinical Psychology, 76, 282-297.

Kendall, P. C., \& Khanna, M. S. (2008a). Camp Cope-A-Lot: The Coping Cat CD Rom [Software]. Available from Workbook Publishing Inc. www. workbookpublishing.com.

Kendall, P. C., \& Khanna, M. S. (2008b). Coach's Manual for Camp Cope-ALot: The Coping Cat CD Rom. Ardmore, PA: Workbook Publishing Inc.

Kendall, P. C., \& Khanna, M. S. (2008c). Go-to-Gadget. Ardmore, PA: Workbook Publishing Inc.

Khanna, M. S., \& Kendall, P. C. (2008). Computer-assisted CBT for child anxiety: The Coping Cat CDROM. Cognitive and Behavioral Practice, 15, 159-165. https://doi.org/10.1016/j.cbpra.2008.02.002

Khanna, M. S., \& Kendall, P. C. (2010). Computer-assisted cognitive behavioral therapy for child anxiety: Results of a randomized clinical trial. Journal of Consulting and Clinical Psychology, 78, 737-745. https://doi.org/10.1037/a0019739 
Khanna, M. S., Kerns, C. M., \& Carper, M. M. (2014). Internet-based dissemination and implementation of cognitive behavioral therapy for child anxiety. In R. S. Beidas \& P. C. Kendall (Eds.), Dissemination and implementation of evidence-based practices in child and adolescent mental health (pp. 313-335). Oxford University Press.

Langley, A. K., Nadeem, E., Kataoka, S. H., Stein, B. D., \& Jaycox, L. H. (2010). Evidence-based mental health programs in schools: Barriers and facilitators of successful implementation. School Mental Health, 2, 105113. https://doi.org/10.1007/s12310-010-9038-1

Locke, J., Lee, K., Cook, C. R., Frederick, L., Vázquez-Colón, C., Ehrhart, M. G., Aarons, G. A., Davis, C., Lyon, A. R. (2018). Understanding the organizational implementation context of schools: A qualitative study of school district administrators, principals, and teachers. School Mental Health, 11, 379-399. http://doi.org/10.1007/s12310-018-9292-1

LoCurto, J., Pella, J., Chan, G., \& Ginsburg, G. (2020). School-based clinicians sustained use of a cognitive behavioral treatment for anxiety disorders. School Mental Health. Advance online publication. http://doi.org/10.1007/s12310-020-09381-y

Lyon, A. R., \& Bruns, E. J. (2019). From evidence to impact: Joining our best school mental health practices with our best implementation strategies. School Mental Health, 11, 106-114. https://doi.org/10.1007/s12310018-09306-w

Lyon, A. R., \& Koerner, K. (2016). User-centered design for psychosocial intervention development and implementation. Clinical Psychology: Science and Practice, 23, 180-200. https://doi.org/10.1111/cpsp.12154

Markle, R. S., Splett, J. W., Maras, M. A., Weston, K. J. (2014). Effective school teams: Benefits, barriers, and best practices. In M. D. Weis, N. A. Lever, C. P. Bradshaw, \& J. S. Owens (Eds.), Handbook of School Mental Health: Research, Training, Practice, and Policy (2nd ed.; pp. 59-73). Springer.

McCrone, P., Knapp, M., Proudfoot, J., Ryden, C., Cavanagh, K., Shapiro, D. A., Ilson, S., Gray, J. A., Goldberg, D., Mann, A., Marks, I., Everitt, B., \& Tylee, A. (2004). Cost-effectiveness of computerised cognitivebehavioural therapy for anxiety and depression in primary care: Randomised controlled trial. The British Journal of Psychiatry, 185, 55-62. https://doi.org/10.1192/bjp.185.1.55 
Mellin, E. A., \& Weist, M. D. (2011). Exploring school mental health collaboration in an urban community: A social capital perspective. School Mental Health, 3, 81-92. https://doi.org/10.1007/s12310-011-9049-6

Merikangas, K. R., He, J., Burstein, M., Swanson, S. A., Avenevoli, S., Cui, L., Benjet, C., Georgiades, K., \& Swendsen, J. (2010). Lifetime prevalence of mental disorders in US adolescents: Results from the National Comorbidity Survey Replication-Adolescent Supplement (NCS-A). Journal of the American Academy of Child \& Adolescent Psychiatry, 49, 980-989. https://doi.org/10.1016/j.jaac.2010.05.017

Merikangas, K. R., He, J., Burstein, M., Swendsen, J., Avenevoli, S., Case, B., Georgiades, K., Heaton, L., Swanson, S., \& Olfson, M. (2011). Service utilization for lifetime mental disorders in US adolescents: Results of the National Comorbidity Survey-Adolescent Supplement (NCS-A). Journal of the American Academy of Child \& Adolescent Psychiatry, 50, 32-45. https://doi.org/10.1016/j.jaac.2010.10.006

Meyer, D. Z., \& Avery, L. M. (2009). Excel as a qualitative data analysis tool. Field Methods, 21, 91-112. https://doi.org/10.1177/1525822X08323985

Morse, J. M. (2007). Qualitative Researchers Don’t Count. Qualitative Health Research, 17(3), 287-287. https://doi.org/10.1177/1049732306297322

Nadeem, E., Jaycox, L. H., Kataoka, S. H., Langley, A. K., \& Stein, B. D. (2011). Going to scale: Experiences implementing a school-based trauma intervention. School Psychology Review, 40, 549-568. http://www.ncbi.nlm.nih.gov/pubmed/27346911

Newman, M. G. (2000). Recommendations for a cost-offset model of psychotherapy allocation using Generalized Anxiety Disorder as an example. Journal of Consulting and Clinical Psychology, 68, 549-555. https://doi.org/10.1037/0022-006X.68.4.549

Olin, S. S., Williams, N., Pollock, M., Armusewicz, K., Kutash, K., Glisson, C., \& Hoagwood, K. E. (2014). Quality indicators for family support services and their relationship to organizational social context. Administration and Policy in Mental Health, 41, 43-54. https://doi.org/10.1007/s10488-013-0499-z

Owens, J. S., Lyon, A. R., Brandt, N. E., Warner, C. M., Nadeem, E., Spiel, C., \& Wagner, M. (2014). Implementation science in school mental health: Key constructs in a developing research agenda. School Mental Health, 6, 99-111. https://doi.org/10.1007/s12310-013-9115-3

Pilkonis, P. A., Choi, S. W., Reise, S. P., Stover, A. M., Riley, W. T., Cella, D., PROMIS Cooperative Group. (2011). Item banks for measuring emotional distress from the Patient-Reported Outcomes Measurement 
Information System (PROMIS $\left.{ }^{\circ}\right)$ : depression, anxiety, and anger. Assessment, 18(3), 263-283. http://doi.org/10.1177/1073191111411667

Powell, B. J., Patel, S. V., Haley, A. D., Haines, E. R., Knocke, K. E., Chandler, S., Katz, C. C., Seifert, H. P., Ake, G., Amaya-Jackson, J., Aarons, G. A. (2019). Determinants of implementing evidence-based traumafocused interventions for children and youth: A systematic review. Administration and Policy in Mental Health, 47, 705-719. http://doi.org/10.1007/s10488-019-01003-3

Reynolds, C. R., \& Kamphaus, R. W. (2002). The clinician's guide to the Behavior Assessment System for Children (BASC). Guilford Press.

Rones, M., \& Hoagwood, K. (2000). School-based mental health services: A research review. Clinical Child and Family Psychology Review, 3, 223-241. https://doi.org/10.1023/A:1026425104386

Rubinson, F. (2002). Lessons learned from implementing problem-solving teams in urban high schools. Journal of Educational and Psychological Consultation, 13(3), 185-217. https://doi.org/10.1207/s1532768xjepc1303_03

Sarver, N. W., Beidel, D. C., \& Spitalnick, J. S. (2014). The feasibility and acceptability of virtual environments in the treatment of childhood Social Anxiety Disorder. Journal of Clinical Child and Adolescent Psychology, 43, 63-73. https://doi.org/10.1080/15374416.2013.843461

Schleider, J. L., Dobias, M. L., Sung, J. Y., \& Mullarkey, M. C. (2019). Future directions in single-session youth mental health interventions. Journal of Clinical Child \& Adolescent Psychology, 49(2), 264-278. http://doi.org/10.1080/15374416.2019.1683852

Stallard, P., Simpson, N., Anderson, S., Hibbert, S., \& Osborn, C. (2007). The FRIENDS emotional health programme: Initial findings from a school-based project. Child and Adolescent Mental Health, 12, 32-37. https://doi.org/10.1111/j.1475-3588.2006.00421.x

Straus, A. L., \& Corbin, J. (1998). Basics of Qualitative Research: Grounded Theory Procedures and Techniques, $2^{\text {nd }}$ edition. Sage Publications.

Sulkowski, M. L., Joyce, D. K., \& Storch, E. A. (2012). Treating childhood anxiety in schools: Service delivery in a response to intervention paradigm. Journal of Child and Family Studies, 21(6), 938-947. https://doi.org/10.1007/s10826-011-9553-1 
Swan, A. J., \& Kendall, P. C. (2016). Fear and missing out: Youth anxiety and functional outcomes. Clinical Psychology: Science and Practice, 23, 417-435. https://doi.org/10.1111/cpsp.12169

Thaker, S., Steckler A., Sánchez, V. , Khatapoush, S., Rose, J., Hallfors, D.D. (2008). Program characteristics and organizational factors affecting the implementation of a school-based indicated prevention program. Health Education Research, 23(2), 238-248. https://doi.org/10.1093/her/cym025

U.S. Department of Education Office of Special Education and Rehabilitative Services. (2002). A new era: Revitalizing special education for children and their families. U.S. Government Printing Office.

Walkup, J. T., Albano, A. M., Piacentini, J., Birmaher, B., Compton, S. N., Sherrill, J. T., Ginsburg, G. S., Rynn, M. A., McCracken, J., Waslick, B., Iyengar, S., March, J. S., \& Kendall, P. C. (2008). Cognitive behavioral therapy, sertraline, or a combination in childhood anxiety. New England Journal of Medicine, 359, $2753-$ 2766. https://doi.org/10.1056/NEJMoa0804633

Whiteside, S. P., Sim, L. A., Morrow, A. S., Farah, W. H., Hilliker, D. R., Murad, M. H., \& Wang, Z. (2020). A meta-analysis to guide the enhancement of CBT for childhood anxiety: exposure over anxiety management. Clinical Child and Family Psychology Review, 23, 102-121. https://doi.org/10.1007/s10567019-00303-2

World Health Organization. (2008). Task shifting: Global recommendations and guidelines. https://www.who.int/workforcealliance/knowledge/resources/taskshifting_guidelines/en/

Wright, J. H., Wright, A. S., Albano, A. M., Basco, M. R., Goldsmith, L. J., Raffield, T., \& Otto, M. W. (2005). Computer-assisted cognitive therapy for depression: Maintaining efficacy while reducing therapist time. The American Journal of Psychiatry, 162, 1158-1164. https://doi.org/10.1176/appi.ajp.162.6.1158

Zenner, C., Herrnleben-Kurz, S., \& Walach, H. (2014). Mindfulness-based interventions in schools—a systematic review and meta-analysis. Frontiers in Psychology, 5, 603. https://doi.org/10.3389/fpsyg.2014.00603 


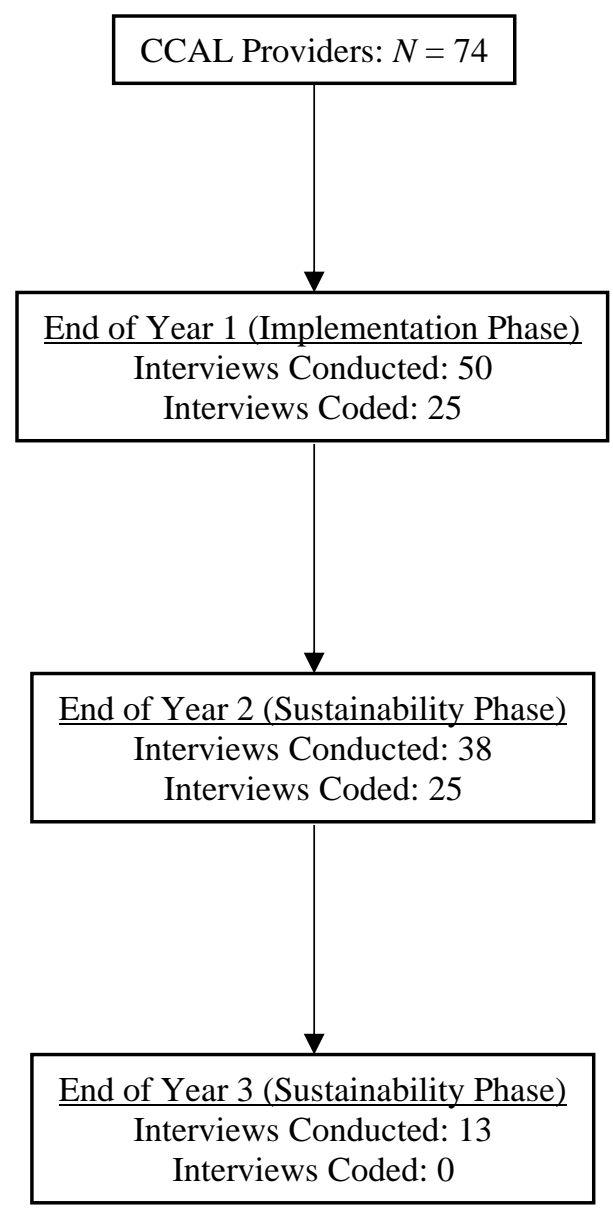

Fig. 1 Participant Flow. CCAL = Camp Cope-A-Lot. Phase 3 interviews were not coded due to participant attrition 
Table 1.

Demographic Characteristics

\begin{tabular}{|c|c|c|}
\hline & $N^{\mathrm{a}}$ & $(\%)$ \\
\hline \multicolumn{3}{|l|}{ PROVIDER CHARACTERISTICS } \\
\hline \multicolumn{3}{|l|}{ Sex } \\
\hline Female & 38 & $(84.4 \%)$ \\
\hline Age (M, SD) & 42.56 & 10.98 \\
\hline \multicolumn{3}{|l|}{ Race } \\
\hline White & 41 & $(91.1 \%)$ \\
\hline Black & 3 & $(6.7 \%)$ \\
\hline Unknown & 1 & $(2.2 \%)$ \\
\hline \multicolumn{3}{|l|}{ Provider Position } \\
\hline Specialized mental health staff & 28 & $(62.2 \%)$ \\
\hline Teacher & 11 & $(24.4 \%)$ \\
\hline Other school staff ${ }^{b}$ & 4 & $(8.9 \%)$ \\
\hline School administrator & 2 & $(4.4 \%)$ \\
\hline \multicolumn{3}{|l|}{ Provider Orientation } \\
\hline Cognitive Behavioral & 10 & $(22.2 \%)$ \\
\hline Humanistic & 4 & $(8.9 \%)$ \\
\hline Eclectic & 4 & $(8.9 \%)$ \\
\hline Psychodynamic & 1 & $(2.2 \%)$ \\
\hline Not applicable & 6 & $(13.3 \%)$ \\
\hline Not reported & 20 & $(44.4 \%)$ \\
\hline \multicolumn{3}{|c|}{ Provider experience treating anxiety } \\
\hline Yes & 23 & $(51.1 \%)$ \\
\hline No & 21 & $(46.7 \%)$ \\
\hline Unknown & 1 & $(2.2 \%)$ \\
\hline
\end{tabular}




\begin{tabular}{lcc}
\hline CLIENT DEMOGRAPHICS $^{c}$ & & \\
\hline Sex & 37 & 62 \\
Male & 8.38 & 1.22 \\
Age (M, SD) & & \\
Race & 42 & 70 \\
White & 1 & 2 \\
Black & 1 & 2 \\
Other (not specified) & 16 & 27 \\
Unknown & & \\
\hline
\end{tabular}

${ }^{\text {a }}$ Total provider $N=45$. ${ }^{\mathrm{b}}$ speech-language pathologist $n=2$, learning disability consultant $n=1$, school nurse $n=1$. ${ }^{\mathrm{c}} \mathrm{Client}$ demographics were reported for 33 out of the 41 providers who saw clients; of these 33 providers, demographics were reported for 60 youth. 
Table 2.

Qualitative Interview Themes and Quotes

\begin{tabular}{|c|c|c|}
\hline Theme & Example Facilitator Quotes & Example Barrier Quotes \\
\hline \multicolumn{3}{|l|}{ Implementation Process } \\
\hline $\begin{array}{l}\text { Training (flexibility, exposures, } \\
\text { wider trainings) }\end{array}$ & $\begin{array}{l}\text { "I thought that the training was excellent and I'm a } \\
\text { hard nut because I design training too. So, I'm very } \\
\text { picky about professional development and I thought it } \\
\text { was excellent." - P1 a }\end{array}$ & $\begin{array}{l}\text { "I would have liked a little bit more training on the program and } \\
\text { specifically exposure tasks." - P2 }\end{array}$ \\
\hline $\begin{array}{l}\text { Consultation (consultant } \\
\text { interpersonal skills, consultation } \\
\text { call content, group consultation, } \\
\text { technical support, and timing) }\end{array}$ & $\begin{array}{l}\text { "They were available all the time. I mean not only the } \\
\text { day of the call, but you could always email with any } \\
\text { questions or contact them any time." - P3 } \\
\text { "I enjoyed hearing what other people had to say, that } \\
\text { was helpful. Like oh okay everybody's in the same } \\
\text { boat, oh okay they're running into the same issues } \\
\text { I'm having." - P4 }\end{array}$ & $\begin{array}{l}\text { "I had a terrible time getting through the supervision calls ... } \\
\text { something would come up or my principal would say we need to do } \\
\text { this, or I need you to take this situation, [and] so I would have to." - } \\
\text { P5 } \\
\text { "I would have rather had } 10 \text { minutes on my own than a half an hour } \\
\text { with other people on the line." - P6 }\end{array}$ \\
\hline $\begin{array}{l}\text { Champions (program promotors; } \\
\text { encouraging program use) }\end{array}$ & $\begin{array}{l}\text { "I think that our school psychologist really pushed } \\
\text { and acknowledged the difficulty with the roll out and } \\
\text { where we went wrong but used his relationships with }\end{array}$ & $\begin{array}{l}\text { "In terms of turnover, we had some teacher positions change, ... but } \\
\text { [Supervisor 1] was pretty instrumental in helping us connect with } \\
\text { your program." - P7 }\end{array}$ \\
\hline
\end{tabular}


people to be able to overcome that, so it didn't get

squashed from the beginning." - P1

\section{Intervention Characteristics}

Treatment Materials (coping skills;

computerized program;

technology problems; program too

long; homework compliance)
"The kids really, really enjoyed being on the

computer, they really, really bought into it. ... The

first 6 weeks with the psychoeducational was really,

really helpful. [With the] challenges, the kids really

experienced a great sense of pride." - P11
"[The major obstacles were] technical problems and time

constraints." - P5

"The student that I had wasn't very responsible for taking [the homework workbook] home and bringing it back, so I didn't send it

home at all. We completed it at the end of the session." - P12

\section{Inner Setting}

\section{School Organizational Factors}

(supportive culture; scheduling;

educational priorities; staff

turnover; staff roles)
"Our teachers, as well as the rest of the staff are willing to try anything if we believe that it can be helpful to a kid, so [...] we are open to trying new things." - P5
Referral Process (anxiety awareness; "I do [think the BASC was helpful]. It made teachers making referrals; BASC use)

more aware of who was anxious in their class otherwise they would have just thought that they were quiet or just a little rambunctious I would say."

$-\mathrm{P} 8$
"Sometimes teachers had a problem with us pulling the kids out at certain times because the curriculum is so jam packed. Any time some of us try to pull [the child], it was a difficult time." - P13

"For the teachers, [the BASC] took a lot of time to do it. I don't know that they felt like it was worth it." - P9

"Some of the teachers might say it was a lot to do a BASC on every kid." - P10 


\section{Characteristics of Individuals Involved}

\begin{tabular}{|c|c|c|}
\hline Administrators (program & "My principal was very supportive and with issues & "I'm an administrator, and I was placed as the service provider. But, \\
\hline implementors; facilitating & like time management, she was always willing to & I think in hindsight, if I had been playing a different role in it, or at \\
\hline scheduling changes; attitudes & support me in any way. If I needed coverage, she & least a partnership, there would've been better communication and a \\
\hline \multirow[t]{2}{*}{ about treatment importance) } & would send a sub in for me if we had one available & better roll out of the program." - P15 \\
\hline & and she was definitely supportive in that way." - P14 & \\
\hline \multirow[t]{9}{*}{ Teachers (scheduling, involvement } & "One teacher was really interested in the idea of & "I don't have time in my schedule. I am a music teacher, and I am \\
\hline & helping to develop the exposure. She actually created & only here a day and half a week, and I am pretty scheduled/ booked \\
\hline & a class assignment to give the student an opportunity & with classes. I don't really have time to pull kids out and work with \\
\hline & for a presentation and whatnot so as not to make him & them on a one-on-one basis. And, I know that's been the struggle \\
\hline & feel singled out." - P16 & for several of us who had originally gotten picked to do this." - P17 \\
\hline & "She was very flexible with the schedule, and she & \\
\hline & knew that Tuesdays at 1 was our time so whatever & \\
\hline & they were doing in the classroom wasn't something & \\
\hline & that was crucial that he could not miss." - P10 & \\
\hline \multirow[t]{4}{*}{ Mental Health Staff (program } & "They were available, they touched base with me. & "It has everything to do with the time that I have, and the amount of \\
\hline & Particularly, Supervisor 2 would check things with & interruptions. Because when I was using Camp-Cope-A-Lot, the \\
\hline & me to see how I was doing and if they got to a certain & student and I would be on the computer trying to get through it, and \\
\hline & point before me, they'd give me some ideas on what & \\
\hline
\end{tabular}


was coming up. If they had run into some challenges, someone is knocking on the door saying, 'well you got to come out they made me aware and vice versa." - P18 and handle this crisis." $\quad$ - P7

CBT Attitudes (doing program gave "I was aware of [CBT] before. Having gone through "One of things that I noticed was that the kids seemed frustrated positive attitudes; EBI techniques; the process with a student, I have greater with their [hierarchy]. There were a lot of options to pick from, so exposure effectiveness; exposure understanding of it, and I feel strongly about how it's they were getting frustrated." - P14 hierarchy) going to be really helpful for some of our students." -

P11

\section{Outer Setting Factors}

Child Clients (engagement; target

age range; client

psychopathology)
"Students were very excited about the program. Most of them that I came in contact with from the service providers that I worked with were excited about it and looked forward to it." - P13

"Th[e] parents that responded to the BASC and filled them out and get them back in a timely manner [were facilitators]." - P13

"I couldn't even get her to focus on the computer when she was really having a tough time. I think what was also difficult was that she was in an acute phase and our goal was definitely to get her back into class. ... We often didn't want to take her out of class when she was back in class." - P19

Parents (supportive of program; returning forms; assisting with homework)
"At this school, the parents were a barrier. We were unable to

implement the program due to them not signing off on the

paperwork." - P20

${ }^{\text {a }} \mathrm{P}=$ participant 